\title{
The report on the
}

\section{$10^{\text {th }}$ The International Conference}

\section{on Education and Educational}

\section{Psychology (ICEEPSY)}

From the 9th - 12th October 2019, the 10th International Conference on Education and Educational Psychology (ICEEPSY) was presented in Barcelona, Spain. The venue was organized by Future Academy from London (UK).

After the registration day (9th October), the conference started with a Poster presentation session (10th October, from 9:00 AM to 10:00 AM), where 26 participants presented their work. During that time, scholars were discussing their research and results with interested persons.

Officially, the conference was opened by Dr Zafer Bekirogullari, Future Academy organization founder and managing director. The first keynote speaker was Lotta UusitaloMalmivaara. Professor Uusitalo-Malmivaara is a university lecturer and adjunct professor in Special Education at the Department of Teacher Education, Faculty of Behavioural Sciences, from the University of Helsinki. Her lecture was entitled Positive education as a tool to engage all learners, where she presented a theoretical background of positive teaching in Finnish schools. The second keynote speaker was Professor Hannele Niemi from the University of Lapland, Finland. Her topic was entitled Combining equity and quality of learning - Educational ecosystems globally and locally. The third keynote speaker was Associate professor Inkeri Ruokonen from the Faculty of Educational Sciences, University of Helsinki, who presented the topic Educating 21st Century Teachers - focusing on learning through the arts in new learning environments.

The third day of the conference started with two parallel workshops from 8:30 AM til 10:30 AM. The first workshop was focused on Creativity and the Arts in Education and it was led by Inkeri Ruokonen and Erika Perttuli-Borobio from the University of Helsinki, Finland. During this workshop, the participants were given some insight into creative methods and interdisciplinary learning in the arts, especially in teacher education. This workshop integrated music and visual art in practical examples and also some cases were presented from Finnish teachers' education. The second parallel workshop had the title Energy of Visual and Verbal Modalities in Language Education. Its leader was 
Maria Stec from the University of Silesia, Poland. The topic was multimodality in early language education, which was presented through the context of learning, communication, visual methodology and perception. Furthermore, the workshop also offered a few drawing tasks to increase one's awareness of image-text relations. It offered tasks related to visual methodology, selection and evaluation of English language teaching materials. The third workshop was from 11:00 AM till 13:00 AM with a title Positive CV, led by Lotta Uusitalo-Malmivaara from the University of Helsinki, Finland. The whole concept of Positive CV is based on an award-winning positive pedagogical solution for recognizing and documenting diverse skills in all students. The main aim is to teach children and adolescents to see all the things they are good at. The participants had to be registered for the workshops in advance and after these sessions, they received an electronic certificate for attending.

Oral presentations were divided to several thematic sections: Second language teaching; The performing arts education, Drama, theatre and dance; Design learning and arts education; Learning theories; Effective teaching practices; Clinical and counselling psychology; Educational psychology; Leadership and collaborative policy; Adult and continuing education; Higher education; Quality assurance/Institutional effectiveness; Sport and exercise education; New approaches in psychology; Teacher education, basic education, basic skills. The oral presentation took place in two parallel sessions. Each oral presentation had a limited time: 15 minutes for presenting research and results and an additional 5 minutes for discussion. Oral presentations session started at 11:00 AM and finished at 5:40 PM.

On the third day of the conference oral presentations were also divided into two parallel sessions and they started at 08:20 AM and finished at 13:40 PM. In total, 66 research papers were presented during two days of oral presentation sessions. Together with poster and oral presentation sessions a virtual presentation session was also realised. This was in the form of online video presentations of research papers and could be viewed during and after the conference via a specific web link opened by registered conference users. There were 16 virtual presentations in total.

This venue, the 10th The International Conference on Education and Educational Psychology (ICEEPSY) was an opportunity for numerous researchers and scholars from various part of the world to present results of their researches and practices from scientific fields of education and psychology. The next ICEEPSY conference will take place at Sicily, Italy in October 2020.

\section{Contact:}

Mgr. Vlado Balaban, Ph.D.

Institute of Education and Social Studies, Faculty of Education

Palacký University in Olomouc

Žižkovo nám. 5, 77140 Olomouc, Czech Republic

E-mail: vlado.balaban02@upol.cz 